\title{
Orocardiodigital syndrome: an oral-facial-digital type II variant associated with atrioventricular canal
}

\author{
Maria Cristina Digilio, Bruno Marino, Aldo Giannotti, Bruno Dallapiccola
}

\begin{abstract}
We report on a patient with a constellation of anomalies including hamartomas of the tongue, polysyndactyly, and atrioventricular canal. A similar association has been previously described by Orstavik et al in two sibs. The clinical spectrum of the oralfacial-digital syndrome (OFDS) type II includes all these features. In particular, congenital heart defect, mainly atrioventricular canal, has been described in a few cases. It has been previously suggested that these latter patients may be affected by a variant of OFDS type II. We propose to distinguish this orocardiodigital variant and point out the association of the syndrome with atrioventricular canal.

(f Med Genet 1996;33:416-418)
\end{abstract}

Key words: oral-facial-digital syndrome; congenital heart defect; atrioventricular canal.

The oral-facial-digital syndromes (OFDS) are heterogeneous conditions with overlapping phenotypic manifestations and difficult clinical classification. ${ }^{1}$ OFDS type II (Mohr syndrome) is an autosomal recessive condition characterised by midline cleft of the upper lip, hamartomas of the tongue, hallucal polysyndactyly, and postaxial polydactyly of the hands. ${ }^{2}$ Congenital heart defect (CHD) has been described in a few patients with OFDS II. ${ }^{34}$ It has been suggested that this association of anomalies may represent a distinct OFDS. ${ }^{5}$ In addition, Orstavik et $a l^{6}$ reported two sibs with CHD, hamartoma of the tongue, and polysyndactyly without the facial dysmorphism characteristic of OFDS.

We report a female patient with a constellation of anomalies similar to that observed by Orstavik et al. ${ }^{6}$ This observation, together with other known patients, suggests a striking association of OFDS II and atrioventricular canal.

\section{Case report}

The proband, a girl, is the first child of healthy, non-consanguineous parents. At the time of delivery the mother was 26 years old and the father 30 years. The family history was unremarkable. The mother's second pregnancy resulted in a healthy boy.

The baby was born vaginally at term after an uncomplicated pregnancy. Birth weight was $3350 \mathrm{~g}$, length $50 \mathrm{~cm}$, and OFC $35 \mathrm{~cm}$. Apgar scores were 8 and 9 at one and five minutes.
A CHD was diagnosed in the first months of life and echocardiography showed a partial atrioventricular canal (AVC) with a cleft of the mitral valve, and a common atrium with a septum between the pulmonary veins and the mitral valve (cor triatriatum type). Oral examination showed three polyps located on the dorsum and lateral rims of the tongue. There was no tongue lobulation or oral cleft. In addition, the baby had postaxial polydactyly and cutaneous syndactyly of fingers 2 and 3 on the left hand and bilateral hallucal polysyndactyly. An imperforate hymen was also noted.

The girl was re-evaluated at 6 years of age. Her weight was $22.4 \mathrm{~kg}$ ( 75 th centile), height $129 \mathrm{~cm}$ ( $>97$ th centile), and OFC $53 \mathrm{~cm}$ (75th
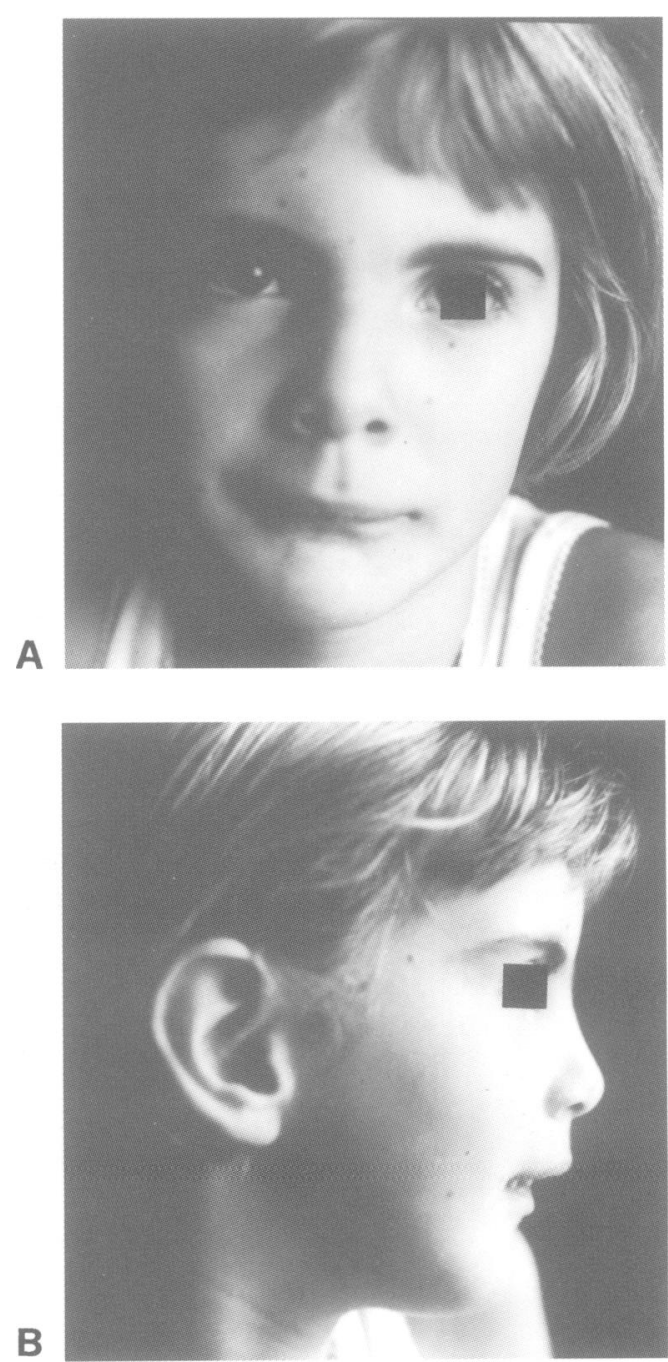

Figure 1 Front $(A)$ and lateral (B) facial appearance of the patient at 6 years of age. 

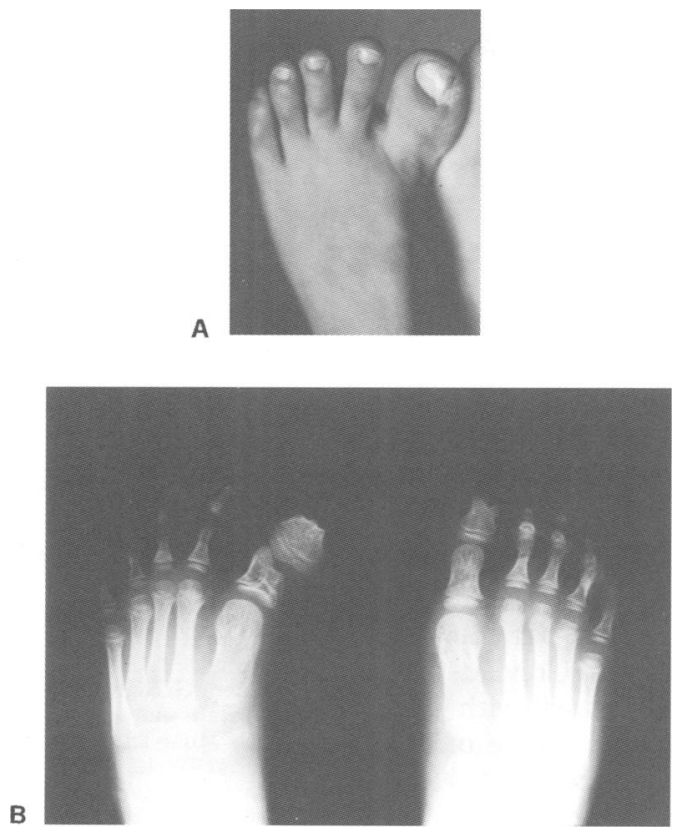

Figure 2 Clinical $(A)$ and $x$ ray $(B)$ appearance of hallucal duplication.

Table 1 Clinical features of patients with specific association of hamartoma of the tongue, polydactyly, and congenital heart defect

\begin{tabular}{|c|c|c|c|}
\hline \multirow[t]{2}{*}{ Clinical feature } & \multicolumn{2}{|c|}{ Orstavik et al ${ }^{6}$} & \multirow{2}{*}{$\begin{array}{l}\text { Present } \\
\text { case }\end{array}$} \\
\hline & Case 1 & Case 2 & \\
\hline \multicolumn{4}{|l|}{ Oral } \\
\hline Tongue hamartoma & + & + & + \\
\hline Cleft tongue & - & - & - \\
\hline Oral frenula & - & - & - \\
\hline Median cleft lip & - & + & - \\
\hline Cardiac & & & \\
\hline Atrioventricular canal & + & - & + \\
\hline Common atrium & - & - & + \\
\hline $\begin{array}{l}\text { Aortic coarctation } \\
\text { Digital }\end{array}$ & + & + & - \\
\hline Hand polydactyly & + & + & + \\
\hline Hand syndactyly & + & - & + \\
\hline Hallucal duplication & + & - & + \\
\hline
\end{tabular}

centile). The facial appearance was mildly dysmorphic including hypertelorism (inner canthal distance $3.5 \mathrm{~cm}=>97$ th centile) and retrognathia (fig $1 \mathrm{~A}$ and $\mathrm{B}$ ). The oral polyps were removed at 7 months of age. On histological examination they were hamartomas. Dental malposition was noted. The extra finger had also been operated on. The feet showed hallucal duplication, more evident on the left where a varus deformity of the big toe (fig $2 \mathrm{~A}$ ) was also present. Intellectual development was normal. Language performance was also considered normal, but speech therapy had been

Table 2 Congenital heart defects in the OFDS

\begin{tabular}{lll}
\hline Genetic condition & Congenital heart defect & Reference \\
\hline OFDS II & AVC, common atrium, truncus arteriosus & 3 \\
& VSD, mitral atresia & 4 \\
& AVC, & 4 \\
& AVC, aortic coarctation & 6 \\
& Aortic coarctation & 6 \\
OFDS II/VI & AVC, common atrium & Present case \\
OFDS IV & AVC & 13 \\
& Common atrium, VSD & 22 \\
& Cor triloculare & 10 \\
OFDS VI & Tetralogy of Fallot & 23 \\
& ASD, mitral valve stenosis & 24 \\
& AVC, aortic coarctation & 9 \\
\hline
\end{tabular}

carried out because of velopharyngeal incompetence. CHD was successfully repaired at 4 years of age.

$X$ ray examination showed a postaxial extra finger on the left and hexodactyly of both feet caused by hallucal duplication. The phalanges of the big toe were duplicated and deviated on the left, while only the distal phalanx was duplicated on the right (fig 2B). No additional skeletal anomalies were seen. Ophthalmological and audiometric evaluations were unremarkable. Cerebral, abdominal, and pelvic ultrasound examinations indicated no abnormalities. Standard chromosome analysis of blood lymphocytes disclosed a normal female karyotype.

\section{Discussion}

Clinical manifestations in our patient strikingly overlap those of case 1 of Orstavik et al, ${ }^{6}$ while case 2 had a less severe phenotype. Interestingly, an AVC was present in our patient and in the first sib of Orstavik et al. ${ }^{6}$ The features of these three cases are summarised in table 1 .

Hamartoma of the tongue and polysyndactyly of the hands and feet are clinical features of OFDS II, IV, VI, and VIII, ${ }^{5}$ while CHDs have been reported in OFDS II, IV, and VI. ${ }^{347-9}$ A diagnosis of OFDS IV or VI can be excluded in our patient. The anomalies found in OFDS IV include mesomelic short limbs with tibial dysplasia, cleft palate, and cerebral anomalies, ${ }^{10}$ while patients with OFDS VI have cerebellar malformation and central polydactyly of the hands. ${ }^{89}$ Another genetic condition with oral and digital involvement, the socalled "postaxial polydactyly-dental-vertebral syndrome"," has been excluded in our girl as neither dental nor vertebral anomalies were present. However, the clinical features found in our patient and in those reported by Orstavik et $a l^{6}$ resemble the oral and digital malformations characteristic of OFDS II, although the facial component is not obvious and CHD is present as an additional abnormality. Clinical heterogeneity of OFDS II has supported the existence of different subtypes, ${ }^{1213}$ including a variant with central nervous system involvement and a transitional type with overlapping features of types II and VI. Cardiac malformations can be associated with OFDS, ${ }^{347-913}$ although it appears that AVC occurs predominantly in OFDS II (table 2). In fact, four out of the six patients labelled as OFDS II with CHD have in effect AVC (present case)..$^{346}$ Detailed clinical features of these patients are

Table 3 Clinical features of patients with oral-facialdigital syndrome II and congenital heart defect

\begin{tabular}{llll}
\hline Clinical features & $\begin{array}{l}\text { Cordero }^{\text {Holmes }^{3}} \\
\end{array}$ & and & \multicolumn{2}{l}{ Iaccarino et al } \\
\cline { 2 - 4 } & & Case 1 & Case 2 \\
\hline Tongue hamartoma & - & - & - \\
Cleft tongue & + & - & - \\
Median cleft lip & + & + & - \\
Epiglottis anomaly & + & + & + \\
Congenital heart defect & + & + & + \\
Hand polydactyly & + & + & + \\
Hallucal duplication & + & & + \\
\hline
\end{tabular}


shown in table 3. None of them was reported to have hamartomas of the tongue. Interestingly, AVC was also present in a fetus with transitional OFDS II/VI. ${ }^{13}$

Based on our results, we propose that OFDS II can be further split to include an orocardiodigital syndrome with hamartoma of the tongue, polysyndactyly of the hands and feet, and CHD, namely AVC. It is well known that AVC occurs as an isolated malformation, but can be associated with non-cardiac anomalies. Although it is occasionally found in children with various aneuploidies and mendelian syndromes, a non-random association of AVC has been noted with specific genetic conditions, including trisomy $21,{ }^{14}$ deletion $8 \mathrm{p},{ }^{15} 3 \mathrm{C}$ syndrome, ${ }^{16}$ and Noonan syndrome. ${ }^{17}$ In addition, AVC is commonly observed in patients with heterotaxia ${ }^{18}$ and Ellis-van Creveld syndrome. ${ }^{1920}$ In particular, children with Ellisvan Creveld syndrome present a type of AVC consisting of a single atrium and partial AVC similar to that reported in the present case and in patients with OFDS II (table 2). Interestingly, AVC is also found in another syndrome with polydactyly of the hands and feet, the Kaufman-McKusick syndrome. ${ }^{21}$

In conclusion, although CHD is not common in OFDS, the existence of a subtype with cardiac involvement is emerging from personal observation and previously reported patients. This orocardiodigital syndrome showing a high frequency of AVC suggests a non-random association of this pattern of malformations. In addition, a specific link between AVC and genetic syndromes with polydactyly is suspected.

1 Toriello HV. Oral-facial-digital syndromes, 1992. Clin Dysmorphol 1993;2:95-105.

2 Rimoin D, Edgerton M. Genetic and clinical heterogeneity in the oral-facial-digital syndromes. $f$ Pediatr 1967;71: in the orat $94-102$.

3 Cordero JF, Holmes LB. Heart malformation as a feature of the Mohr syndrome. $\mathcal{F}$ Pediatr 1977;91:683-4.

4 Iaccarino $M$, Lonardo $F$, Giugliano $M$, Della Bruna $M$ Prenatal diagnosis of Mohr syndrome by ultrasonography. Prenat Diagn 1985;5:415-8.
5 Gorlin RJ, Cohen MM Jr, Levin LS. Syndromes of the head and neck. 3rd ed. New York: Oxford University Press, 1990.

6 Orstavik KH, Lindemann R, Solberg LA, Foerster A, Sorland SJ. Congenital heart defects, hamartomas of the tongue and polysyndactyly in a sister and brother. Clin Genet 1992;42:19-21.

7 Digilio MC, Giannotti A, Pagnotta G, Mingarelli R, Dallapiccola $B$. Joint dislocation and cerebral anomalies are consistently associated with oral-facial-digital syndrome type IV. Clin Genet 1995;48:156-9.

8 Vàradi V, Szabò L, Papp Z. Syndrome of polydactyly, cleft lip/palate or lingual lump, and psychomotor retardation in endogamic gypsies. $\mathcal{J}$ Med Genet 1980;17:119-22.

9 Gustavson KH, Kreuger A, Petersson PO. Syndrome characterized by lingual malformation, polydactyly, tachypnea, and psychomotor retardation (Mohr syndrome). Clin Genet 1971;2:261-6.

10 Meinecke $\mathrm{P}$, Hayek $\mathrm{H}$. Orofaciodigital syndrome type IV (Mohr-Majewski syndrome) with severe expression expanding the known spectrum of anomalies. $\mathcal{f}$ Med Genet 1990;27:200-2.

11 Rogers JG, Levin LS, Dorst JP, Temtamy SA. A postaxial polydactyly-dental-vertebral syndrome. $₹$ Pediatr 1977;90: $230-5$.

12 Haumont D, Pelc S. The Mohr syndrome: are there two variants? Clin Genet 1983;24:41-6.

13 Camera G, Marasini M, Pozzolo S, Camera A. Oral-facialdigital syndrome: report on a transitional type between the Mohr and Vàradi syndromes in a fetus. $A m \mathcal{F} \mathrm{Med}$ Genet 1994;53:196-8.

14 Marino B. Congenital heart disease in patients with Down's syndrome: anatomic and genetic aspects. Biomed Phar syndrome: anatomic and gen
macother 1993;47:197-200.

15 Marino B, Reale A, Giannotti A, Digilio MC, Dallapiccola B. Nonrandom association of atrioventricular canal and del(8p) syndrome. Am f Med Genet 1992;42:424-7.

16 Digilio MC, Marino B, Giannotti A, Mingarelli R, Dallapiccola B. Atrioventricular canal and 3C (cranio-cerebello-cardiac) syndrome. Am $\mathcal{F}$ Med Genet 1995;58:97-8.

17 Marino B, Digilio MC, Gagliardi MG, Giannotti A, Dallapiccola B. Partial atrioventricular canal with left sided lapiccola B. Partial atrioventricular canal with left sided
obstructions in patients with Noonan syndrome. Pediatr Cardiol (in press)

18 Peoples WM, Moller JH, Edwards JE. Polysplenia: a review of 146 cases. Pediatr Cardiol 1983;4:129-38

19 Lynch JI, Perry LW, Takakuwa T, Scott LP. Congenital heart disease and chondroectodermal dysplasia. Report of two cases, one in a Negro. Am 7 Dis Child 1968:115:80-7.

20 Digilio MC, Marino B, Giannotti A, Dallapiccola B. Single atrium, atrioventricular canal/postaxial hexodactyly inatrium, atrioventricular canal/postaxial hexodactyly in96:251-3.

21 McKusick VA, Baier RL, Knoop CE, Scott RB. Hydrometrocolpos as a simply inherited malformation. $\mathfrak{F} A M A$ 1964;189:813-6.

22 Temtamy S, McKusick VA. The genetics of hand malformations. 2nd ed. New York: Alan R Liss for the National Foundation - March of Dimes. Birth Defects 1978; XIV(3):431-7.

23 Gillerot Y. Oro-facial-digital syndrome type II. Clin Genet 1988;33:140-3.

24 Nevin NC, Thomas PS. Orofaciodigital syndrome type IV: report of a patient. Am $\mathcal{F}$ Med Genet 1989;32:151-4. 